\title{
A Conceptual Framework: Organizational Learning, Competencies, and Innovation in Indonesian Digital Startup
}

\author{
Sihar Tigor Benjamin Tambunan ${ }^{1}$, Budiman Christiananta ${ }^{2}$, Dyna Rachmawati ${ }^{3}$ \\ ${ }^{1}$ Sekolah Tinggi Teknik Surabaya, Dept of Industrial Engineering, \\ Ngagel Jaya Tengah 73-77 Surabaya, Indonesia \\ ${ }^{2}$ Universitas Katolik Widya Mandala, Faculty of Economics and Business, \\ Dinoyo 48A - Lt.6, Surabaya, Indonesia \\ ${ }^{3}$ Universitas Katolik Widya Mandala, Faculty of Economics and Business, \\ Dinoyo 48A - Lt.6, Surabaya, Indonesia
}

\begin{abstract}
:
Disruptions carried out by digital startups show a big role of technology-based competencies and innovations. In fact, both are the results of organizational learning. This paper explores a conceptual framework that links organizational learning with performance through competency development and innovation in Indonesian digital startups. A combination of literature studies on organizational learning and some previous research compared with a number of factual conditions of digital startups in Indonesia, resulting in intended conceptual framework.

The authors managed to place technology as a prominent element in each of the proposed variables forming a conceptual framework that links organizational learning with digital startup performance. This conceptual study does not compare the concepts of organizational learning and individual learning in digital startups. Supporting facts used in this study are multi-sector digital startups. So this conceptual framework could be different if applied to specific sectors.

Conceptually, organizational learning has the potential to significantly influence the competency development and innovation in Indonesian digital startups.
\end{abstract}

Keywords: Organizational life cycle, startup, organizational learning, digital competency, innovation, performance

\section{Introduction}

In the 2000s, there was a global phenomenon known as Industry 4.0, a stage of industrial revolution in which various forms of technology were fused so that the boundaries of physical, biological and digital aspects were blurred [1]. The Industry 4.0 is marked by the rise of intelligent products, processes and procedures [2]; and cyber physical system [3]. Since that time, digital startup have emerged with unique organizational phenomena worldwide [4].

Startupranking.com defines digital startup as a company in the introduction stage with a maximum of ten years of categorical age, high innovation competencies, very strong technology-based, capable of growing rapidly, and able to maintain independence for a long time. Startupranking.com recorded 87,312 startups around the world on its official website (http://startupranking.com, accessed December 11, 2018). The growth of digital startups has become a strategic management phenomenon globally. However, there have not been many specific studies conducted to determine the relationship between unique organizational factors in digital startups, especially related to organizational performance. 


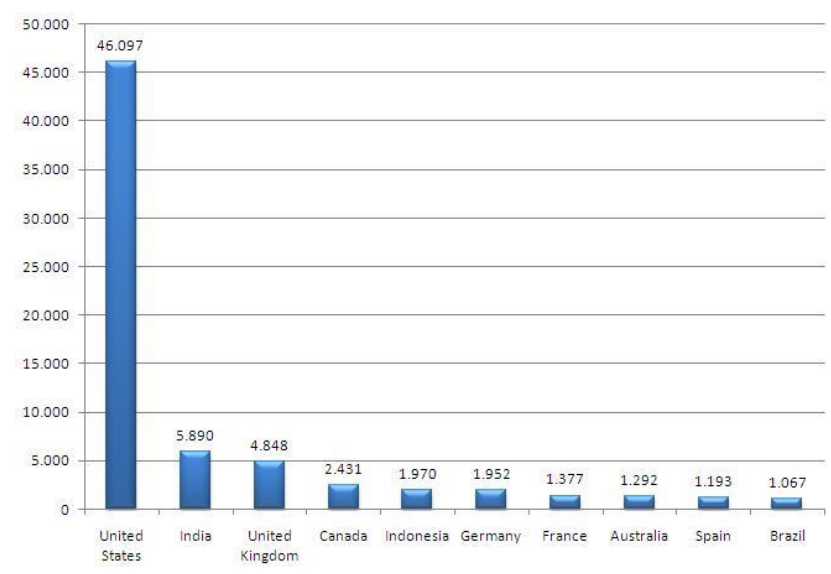

Figure 1: Digital Startups/ country

(Source: Startupranking.com, accessed 11 December 2018: $03.30 \mathrm{pm})$.

McKinsey \& Co Company in its report "Opening digital opportunities for Indonesia" states, although in 2016 the number of internet users in Indonesia was relatively smaller than a number of countries in the world, they were classified as savvy technology. This report is confirmed by startupranking.com which recorded 1,970 Indonesian digital startups in 2018. Startupranking.com ranked Indonesia as the fifth largest startup producer in the world (Figure 1). These are the things that make Indonesia used as regional contextual factor in this proposed conceptual framework.

Theoretically, startup is very fragile. But some facts related to the success of several Indonesian digital startups, raises the allegations of organizational factors that can reduce this fragility. The first factor is organizational learning (OL). According to organizational life cycle (OLC) theory, OL has a minor effect on startups [5]-[7]. Even then, some Indonesian digital startups indicate otherwise.

The second factor is the existence of specific and technology-based competencies. The dominant characteristics of digital knowledge and technology in every product and process [2] and the practical definition of startup according to startupranking.com strengthen the presence of certain competencies at digital startups. A popular article on Forbes mentions three types of roles with very specific competencies in digital startup. These roles are hustlers, hipsters, and hackers. All three must collaborate to maximize digital startup performance.

The third organizational factor concerns the aspect of innovation. OLC theory [5]-[7] does not specifically show the type of prominent innovation in the digital startups. Conventionally, innovation at the startups refers to organizational innovation (OI) rather than technological innovation (TI). In the past,
TI was very expensive. The possibility for startups to make TI is quite small [8].

The last organizational factor was identified from the unique aspects of the digital startup's performance itself. Theoretically there is no definitive explanation of the startups' performance unless the non-financial category is more prominent than finance [8]. Another study concluded that the use of subjective organizational performance (OP) measures was more effective than the use of objective measures. Subjective measures tend to reflect overall OP and can be used as a comparison with competitors [9].

\section{Theoretical background/ literature review}

\subsection{Organizational Life Cycle (OLC)}

The OLC is adopted from the biological life cycle. Over time, each organization will experience changes in organizational characteristics that can be predicted with consistent patterns [7], [10]. Organization will go through several stages of life in its life cycle, namely introduction stage, growth stage, adult stage, and decline stage [5]-[7]. Each stage has unique characteristics and problems that cause different strategic reactions from each organization [7], [11].

Startup is a company in introduction stage. Conventionally, startups are usually small, founded by one person acting as early conceptor of organization and decision makers in almost all functions, very high organizational flexibility and informality [5], [7], [11], more often innovate than other stages [8]. The introduction stage is the most critical stage [10], [12]. Conventional startup need the right resources to survive the next stage.

Digital technology has a strong influence on the characteristics of startup, so-called digital startup [4]. The term digital refers to the characteristics of discrete-based electrical signal technology, based on binary numbers, forming certain codes as representations of information. Digital startup implement various types of high-level science and technology across organizational and business aspects [13], operates in digital entrepreneurial ecosystem [14], and relying heavily on entrepreneurial team competencies [15]-[17]. Digital startups have unique ways of managing resources, speed-oriented in all aspects of their organization and business [17], integrating systems digitally in all directions, and produce smart products [2]. 


\subsection{Organizational Learning (OL)}

To survive, organizations must adapt to the change in their business environment [18]. Organizational adaptability is determined by organization's capability to manage valuable knowledge for recognizing, capturing and changing the opportunities [18], [19]. Capability is always changing, because there is a learning process. This process is depending on the organizational culture [20], [21]. In other words, organizational learning (OL) is an organizational process that produces new expertise or knowledge in organization [22]-[24], permanently changing collective behavior, influencing performance [24], [25], as well as parts of processes to correct past shortcomings [1].

OL occurs when ideas, information, and knowledge are successfully obtained, accessed, shared, discussed, and used by individuals in an organization to create new knowledge [23], [26]. Sources of ideas, information, and knowledge can come from internal and external organizations [27]. OL that occurs systemically will produce a learning organization [28], so that every worker in it is categorized as knowledgeable workers [29].

The process of knowledge acquisition externally and internally, the number of employees in the company who know the knowledge in the company, the number of employees who share knowledge and experience by talking to each other, the availability of formal systems to store ideas and knowledge, the variety of methods to access database within the company, the renewal of the company's database can be used as indicators to recognize the occurrence of OL [27].

\subsection{Competency Development (CD)}

The success of each organization in its life cycle is determined by its ability to choose and make effective use of the resources [30]. In the context of digital economy, the company's physical resources cannot be maintained as an evolutionary asset because it is relatively easy to buy and imitate [31] in contrast to intangible resources such as competency.

Competency is defined as a collection of knowledge, skills, and attributes that everyone needs to carry out their role in an organization [32], [33]. Competency will develop if used and shared, and will fade if not used [34]. Experts have not yet consensus on the type of competencies [34], [35]. Group of competencies can be very different and contextual even though the name is the same. Innovation competencies are oriented towards the organization's internal performance in the Chinese aviation industry
[36], and more external performance oriented for the development of clean production systems in Brazil [37]. Some types of competencies also play a specific role in certain industries [38].

The owner of competencies in digital startup companies also varies. Marketing and business competencies must be owned by hustlers, design competency in hipsters, and technological competency in hackers. Technological based competencies often gets more valuation from potential investors [4].

Because knowledge is the main element of competency [39], a knowledge management system for creating new, high-value, difficult to replicate, and strategic competencies is required. This system is called competency development (CD). CD cannot be measured directly, but through some perceptual indicators of competency identity clarity [40] and diversity of competency functions [35].

\subsection{Organizational Innovation (OI)}

Innovation is defined as the act of creating a new combination to gain competitive advantage [41]. In general, OI is defined as the process of creating and adopting an idea or behavior that is new to an organization [42]. The ability of each member of the organization to adopt knowledge and innovation, develop and disseminate it, both at the group and organizational levels, is the main ingredient of OI. The greater the adoption and diffusion of innovation in groups or organization, the greater the ability of OI [1].

Employee involvement in the OI will be even more intense if the organization confirms innovation as a valuable resource, communicates this [43], and applies organizational culture that strengthens the values of creativity [21]. Organizational support is also often associated with the extent to which a worker feels the organization encourages, recognizes, and rewards people who produce creative ideas in the workplace. This condition will make workers proactive in responding to change, and ultimately produce new ideas in doing things [44].

\subsection{Technological Innovation (TI)}

Each organization reacts differently to technological dynamics that are present in its life cycle [45]. Some parties see the radicalism of technological development as paradoxical. On the one hand, it make the product combining process easy to do [4] and can be used as a tool to attack competitors. On the other hand, it can be a factor that slows down OP 
because it accelerates the process of technological obsolescence in earlier companies, and is easily defeated by newcomers [46]).

TI plays a major role in OP. The contribution of new technologies to various types of performance measures is not always the same. Technology may succeed in increasing work efficiency, but it does not necessarily improve the quality of work [47]. TI concerns the renewal of three intrinsic characteristics of technology, namely platforms, components, and designs [48]. Product innovation, element of TI, is a critical factor for OP [45]; and outcomes of innovation management [31].

In Industry 4.0, technology became much lower in investment with far greater impact on its users. Cloud computing allows anyone to have the capability of digital technology at a very low cost as long as it is connected to the internet [2]. Cloud computing changes the computing system like public infrastructure. Anyone including organizations can utilize cloud computing as an infrastructure, platform, and software. In the context of digital startup, the main target of TI is to aggressively disrupt competitors to the lowest level because their capabilities and assets are obsolete. [31].

\subsection{Organizational Performance (OP)}

$\mathrm{OP}$ is the main outcome of all organizational processes. OP can be grouped based on its objectivity [9]. OP can also be grouped into financial and nonfinancial OP [49], [50]. To assess the OP, clear indicators are required. These indicators measure sales, profits, market share [51]; innovation, efficiency, job satisfaction [49]; customer loyalty and satisfaction [51]. Unfortunately. such indicators are less relevant for the digital startup. At its inception, a digital startup usually experience a lack of financial resources to supplement their productive assets. Throughout the course of its life cycle, the value of the startup's tangible assets is generally smaller than the value of their intangible assets [52].

Initial resources such as business networks, organizational commitment, and heterogeneity of the founders' functional capabilities are determinants of startup sustainability [16], [53]. Given that OL has a greater influence on non-financial OP than finance [49] and subjective measures are more effective in diverse contextual, industrial, time, and economic conditions [9], the use of subjective-non-financial OP indicators is recommended to measure the OP of a digital startup. Efficient product delivery [52], investor trust [54], the legitimacy of the company or how important the role of a company in the social order of society [55] are some OP indicators often used by digital startups.

\section{Research Model and Propositions}

Basically, the proposed conceptual model is the result of a theoretical study of OLC and the five variables discussed in the previous section, which are then compared to the results of several relevant empirical studies (figure 2).

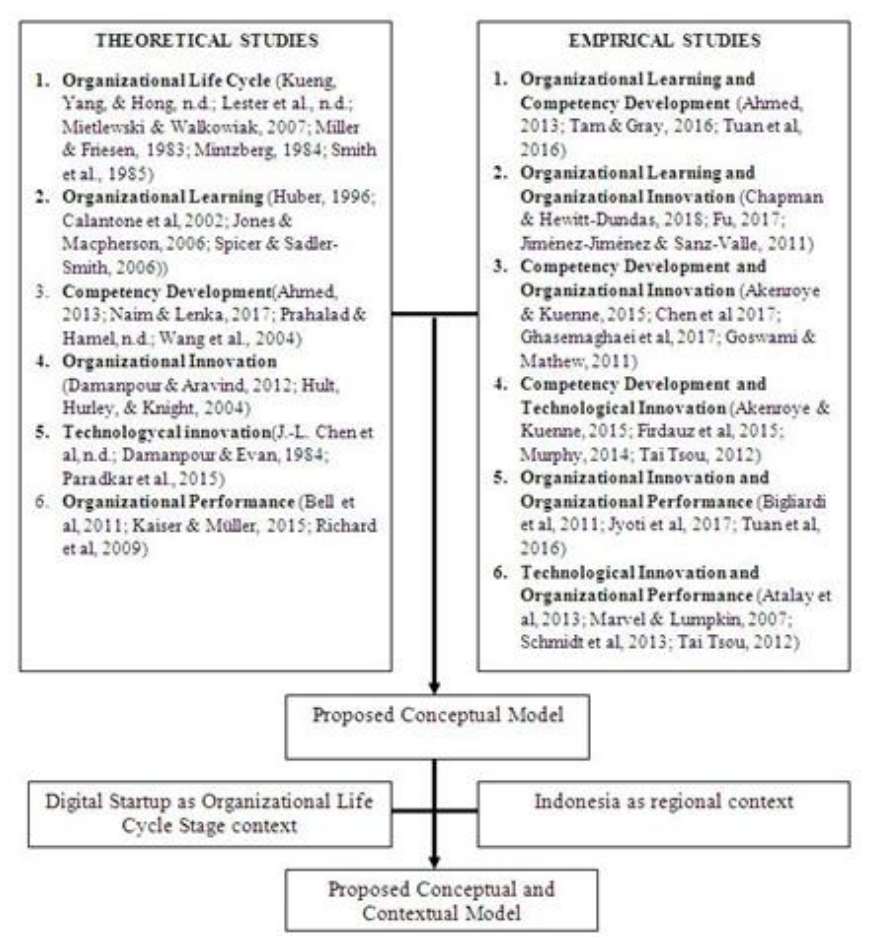

Figure 2: Literature Studies

Factual data of several Indonesian digital startups is used as a basis for the context of the proposed conceptual model.

\subsection{OL and CD}

OLC theory does not explicitly explain CD in the characteristics of a startup, but rather to innovation. [5]-[7]. CD is a strategic process [56], part of organizational dynamic capabilities in the form of the ability to recognize, capture and transform opportunities in organizational resources [19]; ability to renew existing competencies [57], or the ability to integrate existing resources [58]. CD is characterized by an improvement in thinking, methodology, and work output. A study of the effects of OLs on CD in 26 large contractor companies in New South Wales found that each level of OL had a different positive effect on each type of organizational competency [59]. So basically, competency is the result of learning.

In Indonesia context, there are some preliminary evidence that the intensity of OL influences the CD in digital startups. Tokopedia, one of Indonesia's 
unicorns, has implemented OL since its establishment. OL in this online marketplace is carried out on an ongoing basis, through various means, recorded formally using internet technology, similar to the concept of learning according to Huber [18]. Bukalapak, another Indonesian unicorn, conducts digital recruitment on its official website on an ongoing basis. This phenomenon strengthens research findings on the influence of partner match in OL to produce effective technological innovations. [58] Blibli, an Indonesian digital startup even declared itself as a learning organization. Each Blibli employee attends at least seven types of training yearly, technical and organizational. Traveloka, an online beginner digital ticket booking company, another Indonesian unicorn, openly states that they are a technology company, and a place to grow for every talent with strong competencies. Popular digital records show that the performance of each digital startup is the result of the collaboration of hustler, hipsters, and hackers they have. Based on literature studies, empirical studies, and some of the contextual facts, it is proposed that:

\section{P1 : Organizational learning significantly influences the competency development.}

\subsection{OL and OI}

The main element of innovation is knowledge, while knowledge is the result of learning [50]. Thus, logically OI is the result of OL. Digital startups often carry out unique OI compared to conventional startups in Indonesia context. Some are digital organizational habits such as e-meetings, onlineremote jobs, monitoring digital activities online and realtime.

The presence of this digital habits in Indonesian digital startup confirms the need for system-based learning to produce innovation in organizations [60]; innovation as a result of OL [18]; and a study which concludes new habits are OL outcomes [23]. The effect of OL on OI in this study is in line with the theory of innovation which states OI as a result of knowledge-sharing in organizations [29]; findings about the effect of OL on OI in the context of multisector companies in Southeast Spain [50], and similar research in the context of hospitality companies in Taiwan [61]. Based on literature studies, empirical studies, and some of the contextual facts, it is proposed that:

\section{P2 : Organizational learning significantly} influences the organizational innovation.

\section{3. $\mathrm{CD}$ and $\mathrm{OI}$}

The variation in the effect of OL on OI [50], [61], [62] indicates the presence of other factors that mediate both. Because CD is an OL output which also contains the knowledge required by OI, logically $\mathrm{CD}$ has the potential to be a mediating factor between OL and OI. The effect of competency on OI is also contextual [38], [63].

In addition to re-putting OL as one of the typical organizational reactions in its life cycle [7], [11], [45], this conceptual study predicts that OL has a considerable effect and directly to the $\mathrm{CD}$, and directly or indirectly influences OI. The effect of OL on these two different organizational aspects proves that the learning process becomes an institutionalized characteristic of digital startups. Thus a digital startup company is basically a learning organization as initiated by Senge [60], where members renew and expand their capacity continuously in order to achieve the expected results, free to accept new patterns and expansion of thinking, free to learn on an ongoing basis while being given the opportunity to see organizational development holistically, to survive and develop. Based on literature studies, empirical studies, and some of the contextual facts, it is proposed that:

\section{P3 : Competency development significantly influences the organizational innovation.}

\subsection{CD and TI}

OLC theory does not specifically explain the types of innovation that affect startup performance [5]-[7]. Technological innovations are assumed to be too expensive for startups to realize. If the startup's financial condition is not a constraint, or technology is not expensive, then technological innovation has the potential to be realized [1], [2]. Thus, competency development not only influences organizational innovation, but technology innovation as well. Some previous research tends to identify the intensity of technology use as one of the characteristics of digital startup [2], [11], [31], [64], [65]. There is little research on the role of digital technology in digital startup performance.

Some studies indicate that the more often the CD is carried out, the more often TI occur in a digital startup. The most influential competency in this research is technological competency. This competency is not only related to the ability to control or combine various technologies, but also with the ability to effectively mobilize technology in all parts of the organization [32]. The development of technological competency in Indonesian digital 
startup can be categorized as the outcomes of learning system as explained by Senge [60]. Thus, based on literature studies, empirical studies, and some of the contextual facts, it is proposed that:

P4 : Competency development significantly influences the technological innovation.

\subsection{OI and OP}

Practically, startupranking.com uses several nonfinancial performance measures as benchmarks for digital startup rankings in the world or in a country, namely SR Score, SR Web, and SR Social. All three are digital. These measures are very different from the startup performance measures before the 2000s.

Table 1: Ranking of Startups Based on SR Social (May 2018)

\begin{tabular}{|c|c|c|c|c|c|c|}
\hline No & Startup & $\begin{array}{c}\text { World } \\
\text { rank }\end{array}$ & $\begin{array}{c}\text { Country } \\
\text { rank }\end{array}$ & $\begin{array}{c}\text { SR } \\
\text { Score }\end{array}$ & $\begin{array}{c}\text { SR } \\
\text { Web }\end{array}$ & $\begin{array}{c}\text { SR } \\
\text { Social }\end{array}$ \\
\hline 1 & Go-Jek & 254 & 10 & 82.462 & 82.706 & 80.272 \\
\hline 2 & Zalora Indonesia & 133 & 5 & 84.759 & 85.381 & 79.162 \\
\hline 3 & Bolalob & 182 & 8 & 83.793 & 84.348 & 78.800 \\
\hline 4 & Blibli & 66 & 3 & 87.185 & 88.231 & 77.770 \\
\hline 5 & Zenius Education & 266 & 11 & 82.238 & 82.936 & 75.957 \\
\hline 6 & Tokopedia & 32 & 1 & 88.867 & 90.464 & 74.490 \\
\hline 7 & Bukalapak & 47 & 2 & 87.966 & 89.565 & 73.569 \\
\hline 8 & Elevenia & 181 & 7 & 83.818 & 84.974 & 73.406 \\
\hline 9 & Traveloka & 68 & 4 & 87.000 & 88.605 & 72.550 \\
\hline 10 & Mojok.co & 274 & 12 & 82.099 & 83.564 & 68.912 \\
\hline 11 & UrbanIndo & 297 & 14 & 81.877 & 83.472 & 67.521 \\
\hline 12 & Blanja.com & 162 & 6 & 84.147 & 86.435 & 63.548 \\
\hline 13 & Gilabola.com & 324 & 16 & 81.442 & 83.993 & 58.480 \\
\hline 14 & PegiPegi & 309 & 15 & 81.638 & 84.238 & 58.241 \\
\hline 15 & Alodokter.com & 218 & 9 & 83.086 & 86.188 & 55.165 \\
\hline 16 & Rumah & 379 & 19 & 80.782 & 83.686 & 54.651 \\
\hline 17 & Uzone Indonesia & 287 & 13 & 82.011 & 85.070 & 54.484 \\
\hline 18 & DokterSehat & 331 & 17 & 81.394 & 84.432 & 54.049 \\
\hline 19 & Pulsk & 340 & 18 & 81.320 & 84.514 & 52.571 \\
\hline 20 & Mivo & 385 & 20 & 80.670 & 83.898 & 51.615 \\
\hline
\end{tabular}

Source: Startupranking.com, accessed 3 May 2018: 15:15 WIB, data is processed

The SR score (Startupanking Score) reflects the level of influence of a digital startup on the internet and its social environment, the value between 0 100,000 , calculated by a certain formula, based on SR Social and SR web values obtained by a digital startup. SR Social is calculated based on various social sub-parameters in the Facebook and Twitter networks owned by the company. Sub parameters on Facebook include number of likes in the fan page/ post, number of comments on each post, and number of shares. Twitter sub parameters include number of followers, number and quality of retweets. SR Web reflects the level of influence of a digital startup on the internet, its value is between $0-100,000$. SR Web is very dependent on the technological aspects of a digital startup, determined by the number and quality of links that are linked to startup website, on-page
Search Engine Optimization, and other factors related to connectivity.

The ranking of Indonesia digital startups (Table 1) does not necessarily attract potential investors. Go-Jek, an online transportation system provider, despite being ranked 10th in Indonesia, managed to become the 3rd Indonesian unicorn, ahead of thousands more. Go-Jek has the highest SR Social in Indonesia, followed by Zalora Indonesia (online fashion distributor), and Bolalob (soccer information provider). The need for very intense interaction between sellers and buyers (or data providers and users) at Go-Jek, Zalora Indonesia, and Bolalob is expected to make these companies make innovations that have a major impact on SR Social. The diverse SR Social shows the need for several organizational performance indicators based on socio-digital interactions.

The introduction stage is the stage where innovation occurs most frequently and is most influential in organizational life [8]. OLC theories do not specifically explain the type of innovation that affects OP. But in general, the concept of innovations in question leads to OI. Theoretically, OI is inherent in the characteristics of digital startups. Based on literature studies, empirical studies, and some of the contextual facts, it is proposed that:

\section{P5 : Organizational innovation significantly influences the organizational performance.}

\subsection{TI and OP}

Startupranking.com explicitly includes technology as one of the elements of innovation that is very strong in digital startup definition. In fact, the small size and financial capacity do not limit digital startups to innovate technologically. The emergence of smart technologies such as cloud computing, Artificial Intelligence (AI), Cyber Physical System (CPS), and Internet of Things (IoT), makes every organization capable of possessing advanced technological capabilities at very economical costs as long as it is connected to the internet [1], [2], including digital startup.

Table 2: Ranking of Startups based on SR Web (May 2018) 


\begin{tabular}{|c|c|c|c|c|c|c|}
\hline No & Startup & $\begin{array}{c}\text { World } \\
\text { rank }\end{array}$ & $\begin{array}{c}\text { Country } \\
\text { rank }\end{array}$ & $\begin{array}{c}\text { SR } \\
\text { Score }\end{array}$ & $\begin{array}{c}\text { SR } \\
\text { Web }\end{array}$ & $\begin{array}{c}\text { SR } \\
\text { Social }\end{array}$ \\
\hline 1 & Tokopedia & 32 & 1 & 88.867 & 90.464 & 74.490 \\
\hline 2 & Bukalapak & 47 & 2 & 87.966 & 89.565 & 73.569 \\
\hline 3 & Traveloka & 68 & 4 & 87.000 & 88.605 & 72.550 \\
\hline 4 & Blibli & 66 & 3 & 87.185 & 88.231 & 77.770 \\
\hline 5 & Blanja.com & 162 & 6 & 84.147 & 86.435 & 63.548 \\
\hline 6 & Alodokter.com & 218 & 9 & 83.086 & 86.188 & 55.165 \\
\hline 7 & Zalora Indonesia & 133 & 5 & 84.759 & 85.381 & 79.162 \\
\hline 8 & Uzone Indonesia & 287 & 13 & 82.011 & 85.070 & 54.484 \\
\hline 9 & Elevenia & 181 & 7 & 83.818 & 84.974 & 73.406 \\
\hline 10 & Pulsk & 340 & 18 & 81.320 & 84.514 & 52.571 \\
\hline 11 & DokterSehat & 331 & 17 & 81.394 & 84.432 & 54.049 \\
\hline 12 & Bolalob & 182 & 8 & 83.793 & 84.348 & 78.800 \\
\hline 13 & PegiPegi & 309 & 15 & 81.638 & 84.238 & 58.241 \\
\hline 14 & Gilabola.com & 324 & 16 & 81.442 & 83.993 & 58.480 \\
\hline 15 & Mivo & 385 & 20 & 80.670 & 83.898 & 51.615 \\
\hline 16 & Rumah & 379 & 19 & 80.782 & 83.686 & 54.651 \\
\hline 17 & Mojok.co & 274 & 12 & 82.099 & 83.564 & 68.912 \\
\hline 18 & UrbanIndo & 297 & 14 & 81.877 & 83.472 & 67.521 \\
\hline 19 & Zenius Education & 266 & 11 & 82.238 & 82.936 & 75.957 \\
\hline 20 & Go-Jek & 254 & 10 & 82.462 & 82.706 & 80.272 \\
\hline
\end{tabular}

Source: Startupranking.com, accessed 3 May 2018: 15:15 WIB, data is processed

Secondary data in the starturanking.com database presents several interesting phenomena (Table 2). In general the SR Web of each startup is higher than its SR Social. This condition indicates the need for general OP indicators that reflect the influence of TI. The next technological phenomenon is rather individual. For example, even though Traveloka's SR Score is one level below Blibli, Traveloka has a greater SR Web than Blibli (Table 1). These individual facts indicate an indicator of certain TI with a significant impact on OP.

The presence of TI at Indonesian digital startups can be identified from the use of cloud technology as infrastructure (IaaS), platforms (PaaS), and software (SaaS). Tokopedia operates the Virtual Desktop Infrastructure VDI Citrix and a variety of enterpriseclass applications such as Nutanix AHV Hypervisor to run its core applications. Bukalapak develops its digital products continuously. Blibli has radically developed soft-technology since its establishment.

The potential influence of TI on digital startups performance reinforces the statement in OLC theory that each organization reacts differently to environmental changes in each life cycle [7], [11], [45], including the use of technology [45]. The definition of TI according to startupranking.com compared to OLC theory and a number of facts in startup is the reason for the use of TI as the third intervening variable. This variable complements the use of $\mathrm{OI}$ as the second intervening variable that is theoretically inherent in the characteristics of a digital startup. Based on literature studies, empirical studies, and some of the contextual facts, it is proposed that: influences the organizational performance.

The relationship between the five variables is illustrated in the following conceptual model (Figure 3);

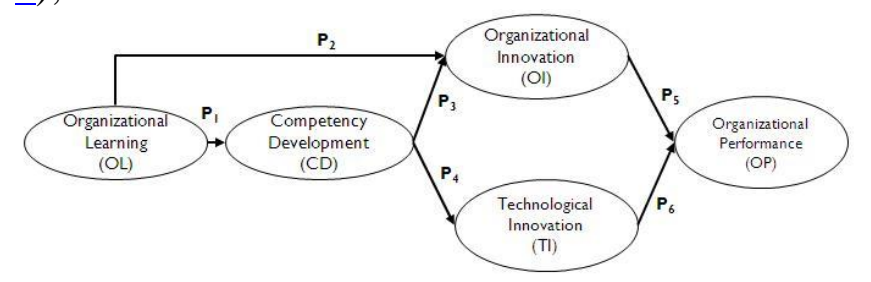

Figure 3: Conceptual Model

\section{Implication for research and practice}

Research on OL in the context of OLC is still rare. These studies generally state that the learning process at the introduction stage is more dominated by individual learning than organizational learning, and has not been institutionalized. These studies generally also ignore the technological context. [5], [66].

The conceptual model (Figure 3) will reveal the role and presence of OL in digital startup according to Huber [18] and OLC theory [7], [11]. The recommended unit of analysis is an organization in the form of a digital startup. The researcher must pay serious attention to the digital characteristics of the unit of analysis and the capabilities of respondents who will represent the unit of analysis. C-level managers who also have a definitive role as hustlers, hipsters, or hackers are highly recommended to ensure the validity of empirical studies. The use of OL, CD, OI, IT, and OP indicators is recommended to be adopted from previous empirical studies that also consider aspects of digital technology.

\section{Limitations and future research directions}

The proposed conceptual model is focused on identifying the intensity of OL according to Huber [18] that occurs in digital startup. This model does not compare the effect of OL with individual learning on the factors discussed earlier. This conceptual model is also proposed in the context of digital startup in Indonesia which has been developing since the 2000s. Different models have the potential to emerge when applied to non-digital startups, even in the Indonesian context. These limitations also open up the opportunity to develop the next conceptual model, including relevant empirical studies. 


\section{Conclusion}

The proposed conceptual model is expected to enrich OLC theory [7], [11], especially regarding the characteristics of OL in digital startups and their contextual factors. Conceptually, OL is predicted to have a strong influence on the development of competencies and innovation.

The proposed model even raises the premise that digital startups in Indonesia can be categorized as learning organizations as stated by Senge [60]. Finally, it is necessary to conduct an empirical study of Indonesian digital startups to validate the proposed conceptual model.

\section{References}

[1] M. Lee et al., "How to Respond to the Fourth Industrial Revolution, or the Second Information Technology Revolution? Dynamic New Combinations between Technology, Market, and Society through Open Innovation," Journal of Open Innovation: Technology, Market, and Complexity, vol. 4, no. 3, p. 21, Jun. 2018.

[2] M. Crnjac, I. Veža, and N. Banduka, "From Concept to the Introduction of Industry 4.0,” p. 10, 2017.

[3] A. Rojko, "Industry 4.0 Concept: Background and Overview," International Journal of Interactive Mobile Technologies (iJIM), vol. 11, no. 5, p. 77, Jul. 2017.

[4] H. Zhong, C. Liu, J. Zhong, and H. Xiong, "Which startup to invest in: a personalized portfolio strategy," Annals of Operations Research, Sep. 2016.

[5] D. Miller and P. H. Friesen, "Successful and Unsuccessful Phases of the Corporate Life Cycle," Organization Studies, vol. 4, no. 4, pp. 339-356, Oct. 1983.

[6] H. Mintzberg, "Power and organization life cycles," Academy of Management review, vol. 9, no. 2, pp. 207-224, 1984.

[7] K. G. Smith, T. R. Mitchell, and C. E. Summer, "Top Level Management Priorities in Different Stages of The Organizational Life Cycle," Academy of Management Journal, vol. 28, no. 4, pp. 799-820, Dec. 1985.

[8] D. L. Lester, J. A. Parnell, and M. L. Menefee, "Organizational Life Cycle and Innovation Among Entrepreneurial Enterprises," vol. 19, no. 2, p. 14, 2008.

[9] S. N. Zulkiffli and N. Perera, "A Literature Analysis on Business Performance For SMEs: Subjective or Objective Measures?," 2011.
[10] S. D. Tsai and T.-T. Lan, "Development of a Startup Business-A Complexity Theory Perspective," 2006.

[11] S. Tam and D. E. Gray, "Organisational learning and the organisational life cycle: the differential aspects of an integrated relationship in SMEs," European Journal of Training and Development, vol. 40, no. 1, pp. 2-20, 2016.

[12] L. Kueng, M.-J. Yang, and B. Hong, "Sources of Firm Life-Cycle Dynamics: Size vs. Age Effects*," p. 37, 2016.

[13] G. Giudici, M. Guerini, and C. Rossi-Lamastra, "The creation of cleantech startups at the local level: the role of knowledge availability and environmental awareness," Small Business Economics, Oct. 2017.

[14] F. Sussan and Z. J. Acs, "The digital entrepreneurial ecosystem," Small Business Economics, vol. 49, no. 1, pp. 55-73, Jun. 2017.

[15] G. N. Chandler, B. Honig, and J. Wiklund, "Antecedents, moderators, and performance consequences of membership change in new venture teams," Journal of Business Venturing, vol. 20, no. 5, pp. 705-725, Sep. 2005.

[16] U. Kaiser and B. Müller, "Skill heterogeneity in startups and its development over time," Small Business Economics, vol. 45, no. 4, pp. 787804, Dec. 2015.

[17] J. Stayton and V. Mangematin, "Startup time, innovation and organizational emergence: A study of USA-based international technology ventures," Journal of International Entrepreneurship, vol. 14, no. 3, pp. 373-409, Sep. 2016.

[18] G. P. Huber, "Organizational learning: The contributing processes and the literatures," Organizational learning, pp. 124-162, 1996.

[19] D. J. Teece, Dynamic capabilities and strategic management: organizing for innovation and growth. Oxford ; New York: Oxford University Press, 2009.

[20] M. Li, Z. Jian, and R. Qin, "The impact of organizational learning and network competence on service innovation performance," in Service Systems and Service Management (ICSSSM), 2016 13th International Conference on, 2016, pp. 1-6.

[21] M. Brettel, C. Chomik, and T. C. Flatten, "How Organizational Culture Influences Innovativeness, Proactiveness, and RiskTaking: Fostering Entrepreneurial Orientation in SMEs," Journal of Small Business 
Management, vol. 53, no. 4, pp. 868-885, Oct. 2015.

[22] R. J. Calantone, S. T. Cavusgil, and Y. Zhao, "Learning orientation, firm innovation capability, and firm performance," Industrial marketing management, vol. 31 , no. 6 , pp. 515524, 2002.

[23] O. Jones and A. Macpherson, "InterOrganizational Learning and Strategic Renewal in SMEs," Long Range Planning, vol. 39, no. 2, pp. 155-175, Apr. 2006.

[24] D. P. Spicer and E. Sadler-Smith, "Organizational learning in smaller manufacturing firms," International Small Business Journal, vol. 24, no. 2, pp. 133-158, 2006.

[25] H.-H. Teo, X. Wang, K.-K. Wei, C.-L. Sia, and M. K. O. Lee, "Organizational learning capacity and attitude toward complex technological innovations: An empirical study," Journal of the American Society for Information Science and Technology, vol. 57, no. 2, pp. 264-279, Jan. 2006.

[26] M. Hernandez, "Assessing Tacit Knowledge Transfer and Dimensions of a Learning Environment in Colombian Businesses," Advances in Developing Human Resources, vol. 5, no. 2, pp. 215-221, May 2003.

[27] S. Pérez López, J. Manuel Montes Peón, and C. José Vázquez Ordás, "Managing knowledge: the link between culture and organizational learning," Journal of knowledge management, vol. 8, no. 6, pp. 93-104, 2004.

[28] P. M. Senge, The fifth discipline: the art and practice of the learning organization, 1. Currency paperback ed. New York, NY: Currency Doubleday, 1994.

[29] I. Nonaka, The knowledge-creating company. Harvard Business Review Press, 2008.

[30] A. A. Oluwatayo, D. Amole, and O. Uwakonye, "Organisational life cycle, business orientation and performances of architectural firms in Nigeria," Construction Economics and Building, vol. 16, no. 1, p. 50, Mar. 2016.

[31] A. Paradkar, J. Knight, and P. Hansen, "Innovation in start-ups: Ideas filling the void or ideas devoid of resources and capabilities?," Technovation, vol. 41-42, pp. 1-10, Jul. 2015.

[32] S. Z. F. Ahmed, "Core Competencies and Phases of The Organizational," vol. 5, no. 1, p. 13, 2013.

[33] M. F. Naim and U. Lenka, "Linking knowledge sharing, competency development, and affective commitment: evidence from Indian Gen Y employees," Journal of Knowledge Management, vol. 21, no. 4, pp. 885-906, Jul. 2017.

[34] C. K. Prahalad and G. Hamel, "The Core Competence of the Corporation," p. 13, 1990.

[35] Y. Wang, H.-P. Lo, and Y. Yang, "The constituents of core competencies and firm performance: evidence from high-technology firms in china," Journal of Engineering and Technology Management, vol. 21, no. 4, pp. 249-280, Dec. 2004.

[36] Y. Zhu, R. Wang, and K. W. Hipel, "Grey relational evaluation of innovation competency in an aviation industry cluster," Grey Systems: Theory and Application, vol. 2, no. 2, pp. 272283, Aug. 2012.

[37] A. M. Vilha and R. Quadros, "Development of new competencies and practices the innovation management to sustainable development: The study of Natura," in Technology Management for the Global Future, 2006. PICMET 2006, 2006, vol. 2, pp. 908-916.

[38] T. O. Akenroye and C. W. Kuenne, "Key Competencies for Promoting Service Innovation: What are Implications for the Health Sector?," vol. 20, p. 21, 2015.

[39] P. Gottschalk, Strategic knowledge management technology. Hershey PA: Idea Group Pub, 2005.

[40] R. Reed and R. J. DeFillippi, "Causal ambiguity, barriers to imitation, and sustainable competitive advantage," Academy of management review, vol. 15, no. 1, pp. 88-102, 1990.

[41] J. A. Schumpeter, The theory of economic development: an inquiry into profits, capital, credit, interest, and the business cycle. New Brunswick, N.J: Transaction Books, 1983.

[42] F. Damanpour and D. Aravind, "Managerial Innovation: Conceptions, Processes and Antecedents," Management and Organization Review, vol. 8, no. 02, pp. 423-454, Jul. 2012.

[43] S. Y. Choi, H. Lee, and Y. Yoo, "The impact of information technology and transactive memory systems on knowledge sharing, application, and team performance: a field study," MIS quarterly, pp. 855-870, 2010.

[44] T. H. D. Varun Grover, "General perspectives on knowledge management: Fostering a research agenda," Journal of management information systems, vol. 18 , no. 1, pp. 5-21, 2001.

[45] J.-L. Chen, S.-J. Liu, C.-H. Tseng, and T. H. Road, "Technological Innovation and Strategy 
Adaptation in the Product Life Cycle," p. 61, 2000.

[46] A. Schmidt, S. G. Walter, and A. Walter, "Radicalness of Technological Inventions and Young Venture Performance-The Role of Technological Competition and Product Diversity," IEEE Transactions on Engineering Management, vol. 60, no. 4, pp. 728-738, Nov. 2013.

[47] M. R. Haas and M. T. Hansen, "Different knowledge, different benefits: toward a productivity perspective on knowledge sharing in organizations," Strategic Management Journal, vol. 28, no. 11, pp. 1133-1153, Nov. 2007.

[48] A. Sood and G. J. Tellis, "Technological evolution and radical innovation," Journal of Marketing, vol. 69, no. 3, pp. 152-168, 2005.

[49] S. C. Goh, C. Elliott, and T. K. Quon, "The relationship between learning capability and organizational performance: A meta-analytic examination," The Learning Organization, vol. 19, no. 2, pp. 92-108, Mar. 2012.

[50] D. Jiménez-Jiménez and R. Sanz-Valle, "Innovation, organizational learning, and performance," Journal of Business Research, vol. 64, no. 4, pp. 408-417, Apr. 2011.

[51] M. L. Santos-Vijande, J. Á. López-Sánchez, and J. A. Trespalacios, "How organizational learning affects a firm's flexibility, competitive strategy, and performance," Journal of Business Research, vol. 65, no. 8, pp. 1079-1089, Aug. 2012.

[52] T. Hasani, J. Bojei, and A. Dehghantanha, "Investigating the antecedents to the adoption of SCRM technologies by start-up companies," Telematics and Informatics, vol. 34, no. 5, pp. 655-675, Aug. 2017.

[53] S. T. Bell, A. J. Villado, M. A. Lukasik, L. Belau, and A. L. Briggs, "Getting Specific about Demographic Diversity Variable and Team Performance Relationships: A MetaAnalysis," Journal of Management, vol. 37, no. 3, pp. 709-743, May 2011.

[54] A. Klabunde, "How much should an investor trust the startup entrepreneur? A network model," Journal of Economic Interaction and Coordination, vol. 11, no. 2, pp. 293-312, Oct. 2016.

[55] T. Chen, L. Qian, and V. Narayanan, "Battle on the Wrong Field? Entrant Type, Dominant Designs, and Technology Exit: Battle on the Wrong Field," Strategic Management Journal, vol. 38, no. 13, pp. 2579-2598, Dec. 2017.
[56] R. G. McGrath, I. C. MacMillan, and S. Venkataraman, "Defining and developing competence: A strategic process paradigm," Strategic management journal, vol. 16, no. 4, pp. 251-275, 1995.

[57] J. Cantwell and R. Mudambi, "MNE competence-creating subsidiary mandates," Strategic management journal, vol. 26, no. 12, pp. 1109-1128, 2005.

[58] H. Tai Tsou, "Collaboration competency and partner match for e-service product innovation through knowledge integration mechanisms," Journal of Service Management, vol. 23, no. 5, pp. 640-663, Oct. 2012.

[59] P. Murray, "Organisational learning, competencies, and firm performance: empirical observations," The learning organization, vol. 10, no. 5, pp. 305-316, 2003.

[60] P. M. Senge, The fifth discipline: the art and practice of the learning organization, 1. Currency paperback ed. New York, NY: Currency Doubleday, 1994.

[61] H.-W. Fu, "Organizational Learning and Organization Innovation in the Tourist Hotels An Empirical Study," Eurasia Journal of Mathematics, Science and Technology Education, vol. 13, no. 9, pp. 6347-6356, Sep. 2017.

[62] G. Chapman and N. Hewitt-Dundas, "The effect of public support on senior manager attitudes to innovation," Technovation, vol. 69, pp. 28-39, Jan. 2018.

[63] S. Goswami and M. Mathew, "Competencies for Organizational Innovation Potential: An Empirical Analysis on Indian Information Technology (IT) Organizations," International Journal of Innovation Management, vol. 15, no. 04, pp. 667-685, Aug. 2011.

[64] A. Nerkar and S. Shane, "When do start-ups that exploit patented academic knowledge survive?," International Journal of Industrial Organization, vol. 21, no. 9, pp. 1391-1410, Nov. 2003.

[65] N. Wasserman, "The throne vs. the kingdom: Founder control and value creation in startups: The Throne vs. the Kingdom," Strategic Management Journal, vol. 38, no. 2, pp. 255277, Feb. 2017.

[66] M. W. Rutherford, P. F. Buller, and P. R. McMullen, "Human resource management problems over the life cycle of small to medium-sized firms," Human Resource Management, vol. 42, no. 4, pp. 321-335, 2003. 


\section{Author Profile}

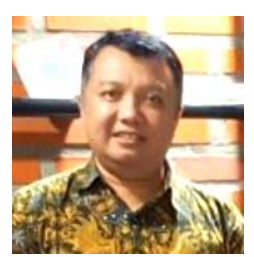

Sihar Tigor Benjamin Tambunan is an associate professor at Sekolah Tinggi Teknik Surabaya (STTS). He holds a master's degree in management from the University of Surabaya. He is a doctoral candidate of Strategic Management in Universitas Katolik Widya Mandala Surabaya. Currently he often interacts with the startup community in Indonesia related to his studies on digital startups 